\title{
Erratum to: Best Matching Theory \& Applications
}

\author{
Mohsen Moghaddam and Shimon Y. Nof
}

\section{Erratum to:}

M. Moghaddam and S.Y. Nof, Best Matching

Theory \& Applications, Automation, Collaboration, \& E-Services 3, DOI 10.1007/978-3-319-46070-3

The original version of the book was inadvertently published without the following corrections:

In Chapter 4, the numbering and indent problems need to be fixed (similar to the other chapters).

In Chapter 6, in Page 133: "Step 4. (Revisited)" should be changed to read as "Step 2. (Revisited)".

In Page 134: Table 6.2 should be placed in the middle of Step 3 (Page 133), right after "...collected during [0,4)—as follows:" ("as follows" refers to that table) In Chapter 7, Table 7.1: The entries of 4th column of 3rd row and 5th row have been aligned as per adjusting the width of the column.

"This book is dedicated to:" is missing in the dedication page and should be updated.

New series cover design to be updated.

The updated original online version for these chapters can be found at

http://dx.doi.org/10.1007/978-3-319-46070-3_4

http://dx.doi.org/10.1007/978-3-319-46070-3_6

http://dx.doi.org/10.1007/978-3-319-46070-3_7

http://dx.doi.org/10.1007/978-3-319-46070-3 